\title{
Relationship between leaf gas-exchange characteristics and the performance of Ziziphus spina-christi (L.) Willd. seedlings subjected to salt stress
}

\author{
M. GORAI ${ }^{*, * *,+}$, R. BEN ROMDHANE*, M. MARAGHNI*, and M. NEFFATI ${ }^{*}$ \\ Laboratory of Pastoral Ecosystems and Valorization of Spontaneous Plants and Associated Microorganisms, Arid \\ Land Institute, University of Gabès, 4119 Médenine, Tunisia* \\ Research Unit of Valorization of Active Biomolecules, Higher Institute of Applied Biology of Medenine, University \\ of Gabes, 4119 Médenine, Tunisia**
}

\begin{abstract}
Ziziphus spina-christi (L.) Willd., known as Christ's thorn jujube, is a multipurpose species of the Rhamnaceae family. Seedlings were subjected to various $\mathrm{NaCl}$ concentrations ( 0 to $200 \mathrm{mM}$ ) for $21 \mathrm{~d}$. They grew well under control conditions, however, biomass production and relative growth rate decreased with increasing $\mathrm{NaCl}$ salinity. This decline in growth was closely associated with a reduction in photosynthetic characteristics and plant water relations. However, the intrinsic water-use efficiency significantly increased as salt stress intensified. The relative water content declined although it still maintained high values $(\geq 57 \%)$. At high salinity, plants displayed more negative stem water potential $\left(\psi_{\mathrm{w}}\right)$ and osmotic potential values of -2.0 and $-4.0 \mathrm{MPa}$, respectively. The net photosynthetic rate and stomatal conductance were positively correlated and the former variable also had a strong positive relationship with $\psi_{\mathrm{w}}$. These findings suggest that this fruit tree is quite tolerant to $\mathrm{NaCl}$-salinity during its seedling stage.
\end{abstract}

Additional key words: Ziziphus spina-christi, growth, salinity, gas exchange, water relations.

\section{Introduction}

Soil salinization has become a serious problem and an environmental issue of worldwide significance. This phenomenon represents about $7 \%$ of the Earth's continental area, $20 \%$ of agricultural lands, and $50 \%$ of cultivated land in the world (Cho et al. 2010), and its frequency is expected to increase as a consequence of climate changes. In arid and semiarid areas, excessive soil salinity is an important constraint limiting plant productivity and their distribution over time and space. The extent of agricultural land, which is affected by high salinity, is increasing worldwide, due to natural phenomena as well as irrigation practices (Munns and Tester 2008). It is estimated that $10 \%$ of the total land area of Tunisia is affected by salinity (Hachicha et al. 1994).

The ability of plants to survive and maintain growth under saline conditions is known as salt tolerance, which is associated with low osmotic potential of soil solution, nutritional imbalance, specific ion effect, hormonal imbalance, and induction of oxidative stress, or a combination of these factors (Parida and Das 2005, Gorai and Neffati 2011). Plants express various responses to salt stress through a multiplicity of ecophysiological features that allow them to cope with contrasting environment, which depend on several interacting variables, including the magnitude (salt concentration and time of exposure) of the stress, plant genotype, plant developmental stage, and cultural environment (Jaleel et al. 2007, Gorai et al. 2011).

Under salt stress conditions, plants manifest acclimation to success their establishment by lowering both leaf water potential $\left(\psi_{\mathrm{w}}\right)$, and osmotic potential $\left(\psi_{\pi}\right)$ (Gorai and Neffati 2011, Gorai et al. 2011). Osmotic adjustment by net accumulation of solutes in cells in response to a fall in the $\psi_{\mathrm{w}}$ of their environment (Ashraf and Foolad 2007) can in part offset this deterioration of growth conditions. As a consequence of this net accumulation, the cell $\psi_{\pi}$ is lowered, and turgor pressure tends to be maintained (Blum et al. 1996). Thus, cell homeostasis is maintained by an osmotic adjustment mechanism which consists of the sequestration of large amounts of salt ions in the vacuole and/or synthesis of organic osmolytes (Munns 2002) involved in protecting subcellular structures and reducing oxidative damage caused by free radicals, produced in response to high salinity (Zhu 2001).

Plant growth depends on the accumulation of carbon products through photosynthesis, but high salinity can adversely affect $\mathrm{CO}_{2}$ and $\mathrm{H}_{2} \mathrm{O}$ exchange (Gorai et al. 2011). Plants decrease the rate of $\mathrm{CO}_{2}$ assimilation as a consequence of the reduced stomatal conductance and/or

Received 11 March 2019, accepted 6 May 2019.

${ }^{+}$Corresponding author; phone: (+216)75633919, fax: (+216)75633918, e-mail: gorai.mustapha@yahhoo.fr

Abbreviations: $C_{\mathrm{i}}$ - intercellular $\mathrm{CO}_{2}$ concentration; DM - dry mass; $E$ - transpiration rate; $\mathrm{FM}$ - fresh mass; $g_{\mathrm{s}}$ - stomatal conductance; $P_{\mathrm{N}}$ - net photosynthetic rate; RGR - relative growth rate; RWC - relative water content; WUE - water-use efficiency; $\mathrm{WUE}_{\mathrm{i}}-$ intrinsic water-use efficiency $\left(=P_{\mathrm{N}} / g_{\mathrm{s}}\right) ; \psi_{\mathrm{p}}$ - turgor potential; $\psi_{\mathrm{w}}-$ water potential; $\psi_{\pi}-$ osmotic potential. 
by direct damage to carbon metabolism (Ashraf 2004, Gorai et al. 2011).

The genus Ziziphus (Rhamnaceae) includes over 100 species of evergreen or deciduous trees or shrubs, usually armed with unequal stipular spines, three of them are found in Tunisia, Z. spina-christi (L.) Willd., Z. vulgaris Lam., and Z. lotus (L.) Lam. (Maraghni et al. 2010). Ziziphus species developed a series of adaptation mechanisms allowing them to tolerate severe conditions. Numerous reports have investigated their physiological and morphological adaptations to water deficit stress (e.g., Clifford et al. 1998, Arndt et al. 2001, Kulkarni et al. 2010, Maraghni et al. 2014, 2019) and salt stress (e.g., Gupta et al. 2002, Bhatt et al. 2008, Sohail et al. 2009, Agrawal et al. 2013, Shekafandeh and Takhti 2013).

Z. spina-christi, known as Christ's thorn jujube, is a multipurpose tree with edible fruits. It is cross-pollinated plant and highly outbred (Sudhersan and Hussain 2003). Establishment of Ziziphus species is constrained by poor germination and seedling emergence, mainly as a result of a stony endocarp, and dormancy types (Maraghni et al. 2010). Finch-Savage and Leubner-Metzger (2006) suggested that seeds of Rhamnaceae family presented non-dormancy, physiological (PD), physical (PY), and combinational (PY+PD). Under natural conditions, stone passage through the digestive tract of vertebrates is critical for endozoochorus seed dispersal because it enhanced germination for some Ziziphus species (Saied et al. 2008). The introduction of this species in agroforestry systems requires a good understanding of its ecophysiological behavior under restrictive environmental conditions. The plant is well adapted to dry and hot climates, but little is known about the physiological basis at the seedling stage under salt stress conditions. Analysis of the relationship between gas-exchange characteristics and plant-water relations provides a tool for understanding how plants cope with $\mathrm{NaCl}$ salinity, and how the mechanisms of adaptation to excessive soil salinity may affect its prospects for cultivation, restora-tion, and persistence in natural ecosystems in the face of climate change. Our primary hypothesis stated that seedlings subjected to $\mathrm{NaCl}$ salinity should display a trade-off between water loss and carbon gain allowing them to survive in contrasting environments. We aimed to identify the relationship between leaf gas-exchange characteristics, water relations, and the performance of Christ's thorn jujube seedlings.

\section{Materials and methods}

Plant material, growth conditions, and experimental design: Seeds of Ziziphus spina-christi (L.) Willd. were provided by the seed bank of the Laboratory of Pastoral Ecosystems and Valorization of Spontaneous Plants and Associated Microorganisms at the Arid Land Institute, Médenine, Tunisia. Fruits were obtained from six wild individual trees which were collected from a location in Tozeur (southwest Tunisia). This area is Saharan with a typical Mediterranean climate, characterized by irregular rainfall events and a harsh dry summer period. Annual rainfall is around $93.47 \mathrm{~mm}$, mean annual temperature is $22.6^{\circ} \mathrm{C}$ with a minimum temperature $1.8^{\circ} \mathrm{C}$ in January and $47.6^{\circ} \mathrm{C}$ maximum in August.

When experiments were carried out, fruit pulps were removed and endocarps were cracked using a manual peeler. The stones contain two seeds embedded in the endocarp. Germinated seeds were transferred to 1-L plastic pots perforated at the bottom to facilitate drainage. A commercial peat (type Floragard) was used as a substrate with the following physicochemical characteristics: dry matter of $25-40 \%$, organic material of $55-90 \%$, water retention capacity of $50-78 \%$, electrical conductivity(EC) of $0.62 \mathrm{mS} \mathrm{cm}^{-1}$, and $\mathrm{pH}=5.5-6$. Watering was carried out every $2 \mathrm{~d}$ by rainwater with very low EC. Seedlings were grown in a growth chamber as follows: temperature of $25 \pm 1{ }^{\circ} \mathrm{C}, 50 / 70 \%$ day/night relative humidity, and $16-\mathrm{h}$ light/8-h dark regime with PAR of $250 \mu \mathrm{mol}$ (photon) $\mathrm{m}^{-2} \mathrm{~s}^{-1}$. The experiment was arranged in a completely randomized design with four $\mathrm{NaCl}$ salinity treatments $\times$ five replicates. Seedlings were supplied with rain water $(0 \mathrm{mM} \mathrm{NaCl}$, $\mathrm{EC}=0.78 \mathrm{mS} \mathrm{cm} \mathrm{cm}^{-1}$ ) lacking salt or the same solution supplemented with 50, 100 or $200 \mathrm{mM} \mathrm{NaCl}$. To avoid osmotic shock, $\mathrm{NaCl}$ concentrations were increased stepwise in aliquots of $50 \mathrm{mM}$ per day.

Growth measurements: Two harvests were carried out, at the beginning of the treatment (45-d-old plants) and $21 \mathrm{~d}$ later. At the harvests, leaves, stems, and roots were successively rinsed three times in cold water and blotted between two layers of filter paper. The fresh mass (FM) was measured immediately, and the dry mass (DM) after $48 \mathrm{~h}$ of desiccation in an oven at $60^{\circ} \mathrm{C}$. Plant relative growth rate $\left(\mathrm{RGR}\left[\mathrm{d}^{-1}\right]\right)$ was determined as: $\mathrm{RGR}=\Delta \mathrm{M} / \underline{\mathrm{M}} \Delta \mathrm{t}$, where $\Delta$ is the difference between values at the final and initial harvests, $\mathrm{t}$ is the time [d], and $\mathrm{M}$ is the whole plant $\mathrm{DM}[\mathrm{g}] . \underline{\mathrm{M}}$ is the logarithmic mean of $\mathrm{M}$ calculated over the $\Delta \mathrm{t}$ period (Hunt 1990): $\underline{\mathrm{M}}=\Delta \mathrm{M} / \Delta \ln (\mathrm{M})$.

Plant water relations: The water status was evaluated by measuring relative water content (RWC [\%]) on fully expanded leaves according to Morgan (1984): RWC = $[(\mathrm{FM}-\mathrm{DM}) /(\mathrm{TM}-\mathrm{DM}) \times 100]$, where FM, DM, and TM are the fresh, dry, and turgid masses, respectively. Stem $\psi_{\mathrm{w}}[\mathrm{MPa}]$ was measured using a pressure chamber (PMS Instruments Co., Corvallis, OR, USA) after $21 \mathrm{~d}$ of salt treatment, according to Scholander et al. (1965). After the measurement of $\psi_{\mathrm{w}}$, the samples were frozen in liquid nitrogen and stored at $-20^{\circ} \mathrm{C}$. Leaf tissues were thawed and centrifuged at $1,200 \times g$ for $25 \mathrm{~min}$ at $4^{\circ} \mathrm{C}$ to extract the cell sap. A vapor pressure osmometer (Wescor 5520, Logan, UT, USA) was used to determine osmolality of the sap expressed from leaves, which was converted to $\psi_{\pi}[\mathrm{MPa}]$, by the van't Hoff equation: $\psi_{\pi}=-c i \mathrm{R} \mathrm{T}$, where $c i$ is the value read from the instrument, $\mathrm{R}$ is the ideal gas constant, and $\mathrm{T}$ is the absolute temperature (Nobel 1991). Turgor potential $\left(\psi_{\mathrm{p}}[\mathrm{MPa}]\right)$ was determined using the relationship: $\psi_{\mathrm{p}}=\psi_{\mathrm{w}}-\psi_{\pi}$.

$\mathrm{CO}_{2}$ and $\mathrm{H}_{2} \mathrm{O}$ gas exchange: The net photosynthetic rate 
$\left(P_{\mathrm{N}}\left[\mu \mathrm{mol}\left(\mathrm{CO}_{2}\right) \quad \mathrm{m}^{-2} \mathrm{~s}^{-1}\right]\right)$, stomatal conductance $\left(g_{\mathrm{s}}\right.$ $\left.\left[\mathrm{mol}\left(\mathrm{H}_{2} \mathrm{O}\right) \mathrm{m}^{-2} \mathrm{~s}^{-1}\right]\right)$, transpiration rate $\left(E\left[\mathrm{mmol}\left(\mathrm{H}_{2} \mathrm{O}\right)\right.\right.$ $\left.\left.\mathrm{m}^{-2} \mathrm{~s}^{-1}\right]\right)$, and intercellular $\mathrm{CO}_{2}$ concentration $\left(C_{\mathrm{i}}\right.$ $\left.\left[\mu \mathrm{mol}\left(\mathrm{CO}_{2}\right) \mathrm{mol}^{-1}\right]\right)$ of fully expanded leaves were measured between 10:00 and 12:00 h using an LCpro+ portable photosynthesis system (ADC, BioScientific Ltd, UK). The $\mathrm{CO}_{2}$ concentration in the leaf chamber was set at $360 \mu \mathrm{mol} \mathrm{mol}{ }^{-1}$ and the leaf was irradiated with a light intensity of $1,500 \mu \mathrm{mol}$ (photon) $\mathrm{m}^{-2} \mathrm{~s}^{-1}$. The water-use efficiency [WUE, $\mu \mathrm{mol}\left(\mathrm{CO}_{2}\right) \mathrm{mmol}\left(\mathrm{H}_{2} \mathrm{O}\right)^{-1}$ ] and intrinsic $\left[\mathrm{WUE}_{\mathrm{i}}, \mu \operatorname{mol}\left(\mathrm{CO}_{2}\right) \operatorname{mol}\left(\mathrm{H}_{2} \mathrm{O}\right)^{-1}\right]$ were calculated as $P_{\mathrm{N}} / E$ and $P_{\mathrm{N}} / g_{\mathrm{s}}$, respectively.

Statistical analysis: Data were analysed using SPSS v. 17.0. They were tested for normal distribution using the Shapiro-Wilk's test, and heterogeneities of variance within treatments were tested using Levene's test. Tukey's test (honestly significant differences, HSD) was used to estimate the least significant range between means. Correlation coefficients between pairs of growth and physiological attributes were examined using Pearson's correlation coefficient at 5 or $1 \%$ significance level.

\section{Results}

Growth attributes: The $\mathrm{NaCl}$ salinity affected development and growth of seedlings at the highest concentration (200 $\mathrm{mM} \mathrm{NaCl}$ ), which was associated with the appearance of foliar necrosis. A one-way ANOVA indicated that salinity significantly affected the average leaf number (Fig. $1 A ; F=$ $5.69 ; P<0.01)$. The average number just before the applied stress was $c a$. eight leaves per plant. At the final harvest, the leaf number on salt-free medium was four times higher relative to original plants, whereas in the presence of $200 \mathrm{mM}$, this parameter represented $\mathrm{ca} .50 \%$ of the control value. As shown in Fig. 1 $B$, plants grew optimally under control conditions $(28.2 \mathrm{~cm})$, and their height significantly decreased as salt stress intensified $(F=25.01 ; P<0.01)$. The average plant height was considerably reduced at $200 \mathrm{mM} \mathrm{NaCl}$ (ca. $69 \%$ of the control plants).
The presence of $\mathrm{NaCl}$, even at low concentration $(50 \mathrm{mM})$, caused a decrease in the dry matter of whole plants of $c a .27 \%$ as compared to control plants. This decline in dry mass was more pronounced at the highest $\mathrm{NaCl}$ concentration ( $\mathrm{ca} .55 \%$ of the control value, Fig. $1 \mathrm{C}$ ). The RGR followed a similar trend for dry matter allocation and decreased significantly in all tissues at the highest $\mathrm{NaCl}$ concentration. At all levels of salinity, roots had the lowest growth activity. A one-way ANOVA on the biomass production indicated that salinity significantly affected DM (ANOVA $F$ values 12.10, 10.22, 5.40 for leaves, stems, and roots, respectively, and all $P<0.01)$ and RGR (ANOVA $F$ values 12.78, 11.73, 4.76 for leaves, stems, and roots, respectively, and all $P<0.05)$. The RGRs of different organs were reduced by $c a .27-71 \%$ as compared to control plants, depending on the $\mathrm{NaCl}$ concentration of the growth medium.

Water relations: The RWC was significantly reduced by $7-21 \%$ compared to control plants after $21 \mathrm{~d}$ of the salt stress treatment $(F=10.67, P<0.001$; Fig. 2$)$. A one-way $A N O V A$ of the water status revealed that $\mathrm{NaCl}$ salinity significantly affected $\psi_{\mathrm{w}}, \psi_{\pi}$, and $\psi_{\mathrm{p}}($ ANOVA $F$ values $24.96,64.56,11.21$, respectively, and all $P<0.001)$ of salinized plant relative to control ones. There were strong linear relationships between parameters of the plant water potential and the $\mathrm{NaCl}$ concentration of the watering solutions (Fig. $3 A-C$ ). Negative relationships were identified for $\psi_{\mathrm{w}}$ and $\psi_{\pi}$ (R2 values of 0.82 and 0.90 , respectively; Fig. $3 A, B)$, whereas a positive relationship was found for $\psi_{\mathrm{p}}(\mathrm{R} 2=0.63$; Fig. $3 C)$. The average value of $\psi_{\mathrm{w}}$ dropped from -0.81 to $-2.01 \mathrm{MPa}$ at 0 and $200 \mathrm{mM}$ $\mathrm{NaCl}$, repectively. A similar pattern was observed in $\psi_{\pi}$ but there was an additional decline from -1.89 to $-4.0 \mathrm{MPa}$. There was a significant positive correlation between $\psi_{\mathrm{w}}$ and $\psi_{\pi}\left(R^{2}=0.82, P<0.01\right)$. According to the relationship $\psi_{\mathrm{w}}=$ $\psi_{\pi}+\psi_{\mathrm{p}}, \psi_{\mathrm{p}}$ corresponding to the difference between each point response and the line of equality at any value of $\psi_{\mathrm{w}}$. Stem $\psi_{\pi}$ decreased with decreases in $\psi_{\mathrm{w}}$ and the proximity of points to the zero line showed that variations in $\psi_{\mathrm{p}}$ were

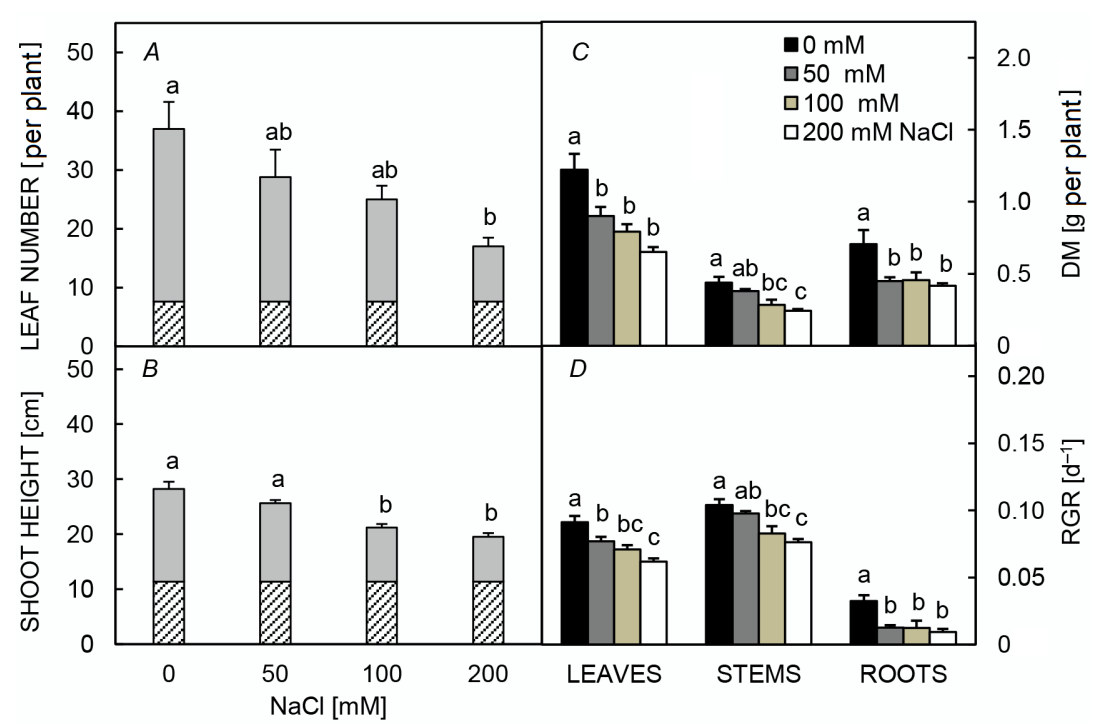

Fig. 1. Changes in leaf number $(A)$, shoot height $(B)$, dry mass $(\mathrm{DM})(C)$, and relative growth rate (RGR) $(D)$ of Ziziphus spinachristi seedlings subjected for $21 \mathrm{~d}$ to various $\mathrm{NaCl}$ concentrations $(0,50,100$ or $200 \mathrm{mM})$. Values are means $\pm \mathrm{SE}, n=5$. Hatched histograms correspond to the initial leaf number and shoot height before $\mathrm{NaCl}$ treatments. The same letters indicate no significant differences $(P<0.05)$ according to the Tukey's test. 


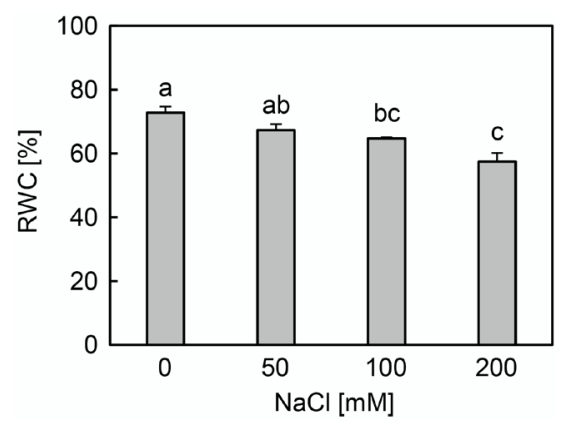

Fig. 2. Changes in leaf relative water content (RWC) of Ziziphus spina-christi seedlings subjected for $21 \mathrm{~d}$ to various $\mathrm{NaCl}$ concentrations $(0,50,100$ or $200 \mathrm{mM})$. Values are means $\pm \mathrm{SE}$, $n=5$. The same letters indicate no significant differences $(P<0.05)$ according to the Tukey's test.

smallest for control plants and largest for $\mathrm{NaCl}$-stressed plants after $21 \mathrm{~d}$, likely to be due to osmotic adjustment (Fig. 3D).

$\mathrm{CO}_{2}$ exchange, transpiration, and stomatal conductance: A one-way $A N O V A$ showed that $\mathrm{NaCl}$ salinity significantly affected $P_{\mathrm{N}}, C_{\mathrm{i}}, E$, and $g_{\mathrm{s}}(F$-values $39.16,9.39,20.26$, and 18.22 , respectively; $P<0.01$ ). There was a significant negative relationship between $\mathrm{NaCl}$ concentration of watering solutions and $P_{\mathrm{N}}, C_{\mathrm{i}}, E$, and $g_{\mathrm{s}}$ with $r$ values of $0.85,0.63,0.73$, and 0.69 , respectively (Fig. $4 A-D$ ). The $P_{\mathrm{N}}$ significantly decreased with the increase in osmolarity of solutions ( $c a .19$ and $67 \%$ of the control value at 50 $\mathrm{mM}$ and $200 \mathrm{mM} \mathrm{NaCl}$, respectively). The $C_{\mathrm{i}}$ was reduced by $13-45 \%$ relative to control plants, when the medium $\mathrm{NaCl}$ concentration increased. The $E$ was severely reduced as salt stress intensified. The highest average rate was recorded in control plants $\left[1.73 \mathrm{mmol}\left(\mathrm{H}_{2} \mathrm{O}\right) \mathrm{m}^{-2} \mathrm{~s}^{-1}\right]$, and approximately fourfold lower rate in plants stressed at $200 \mathrm{mM} \mathrm{NaCl}$ (Fig. 4C). As compared to controls, $g_{\mathrm{s}}$ of salt-treated plants decreased by $c a .31$ and $83 \%$ at $50 \mathrm{mM}$ and $200 \mathrm{mM} \mathrm{NaCl}$, respectively (Fig. 4D). This decline was more pronounced than those in $P_{\mathrm{N}}$ and $E$ with increasing $\mathrm{NaCl}$ concentration. Stressed plants displayed higher $P_{\mathrm{N}} / E(\mathrm{WUE})$ and $P_{\mathrm{N}} / g_{\mathrm{s}}\left(\mathrm{WUE}_{\mathrm{i}}\right)$ ratios than that in control plants, where the differences become significant with increasing $\mathrm{NaCl}$ concentration of watering solutions $(F=4.71, P<0.05 ; F=8.70, P<0.01$, respectively; Fig. $4 E, F)$, with $r$ values 0.41 and 0.57 , respectively.

The correlation coefficients between growth and different physiological attributes are shown in Table 1. As expected, high correlation coefficients were found between growth (shoot DM and shoot RGR) and all photosynthetic parameters of plants except WUE, when exposed to $\mathrm{NaCl}$ salinity at varying concentration of watering solutions. Additionally, the plant water potential components $\left(\psi_{\mathrm{w}}\right.$, $\psi_{\pi}$, and $\psi_{\mathrm{p}}$ ) and the RWC showed highly significant correlation coefficients with shoot DM, revealing strong relationships (shoot DM $\times \psi_{\mathrm{w}}, r=0.79$; shoot DM $\times \psi_{\pi}$, $r=0.82$; shoot $\mathrm{DM} \times \psi_{\mathrm{p}}, r=0.67$; shoot $\mathrm{DM} \times \mathrm{RWC}$, $r=0.75)$.

\section{Discussion}

The Christ's thorn jujube plants grew optimally under control conditions and at moderate salinity in comparison with high $\mathrm{NaCl}$ salinity $(200 \mathrm{mM})$. The depressive effect of salinity on plant growth was more pronounced at the highest $\mathrm{NaCl}$ concentration. This was in agreement with previous reports on Ziziphus species including Z. spina-christi at 180
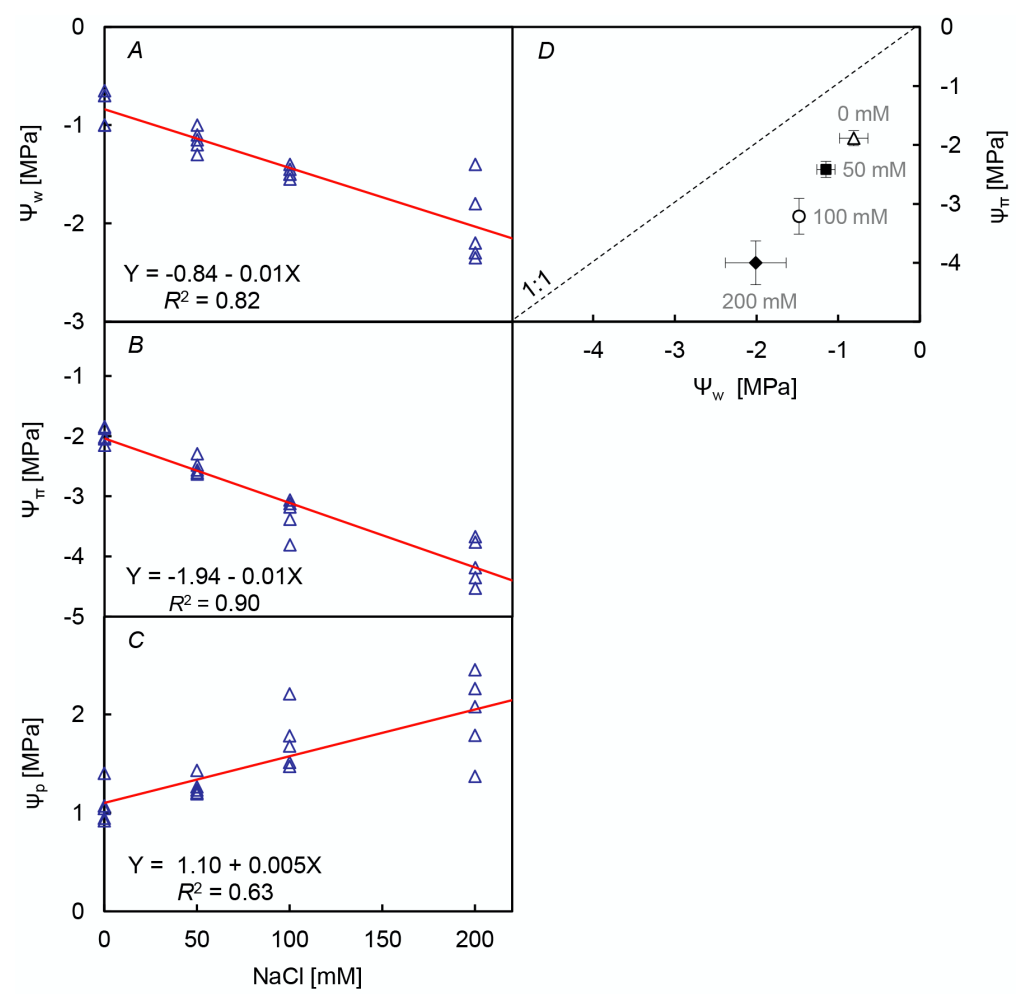

Fig. 3. Regression plots for water potential $\left(\psi_{\mathrm{w}}\right)$ $(A)$, osmotic potential $\left(\psi_{\pi}\right)(B)$, and turgor potential $\left(\psi_{\mathrm{p}}\right)(C)$, and relationship between $\psi_{\mathrm{w}}$ and $\psi_{\pi}$ (D) in leaves of Ziziphus spina-christi seedlings subjected for $21 \mathrm{~d}$ to various $\mathrm{NaCl}$ concentrations $(0,50,100$ or $200 \mathrm{mM})$. Lines describing the dependencies were obtained using a linear regression. $A-C$ : Values are from four treatments with five replicates $(n=20)$. $D$ : Values represent means $\pm \mathrm{SE}$ $(n=5)$. The 1:1 line indicates $\psi_{\pi}=\psi_{\mathrm{w}}$ and hence $\psi_{\mathrm{p}}=0$. 


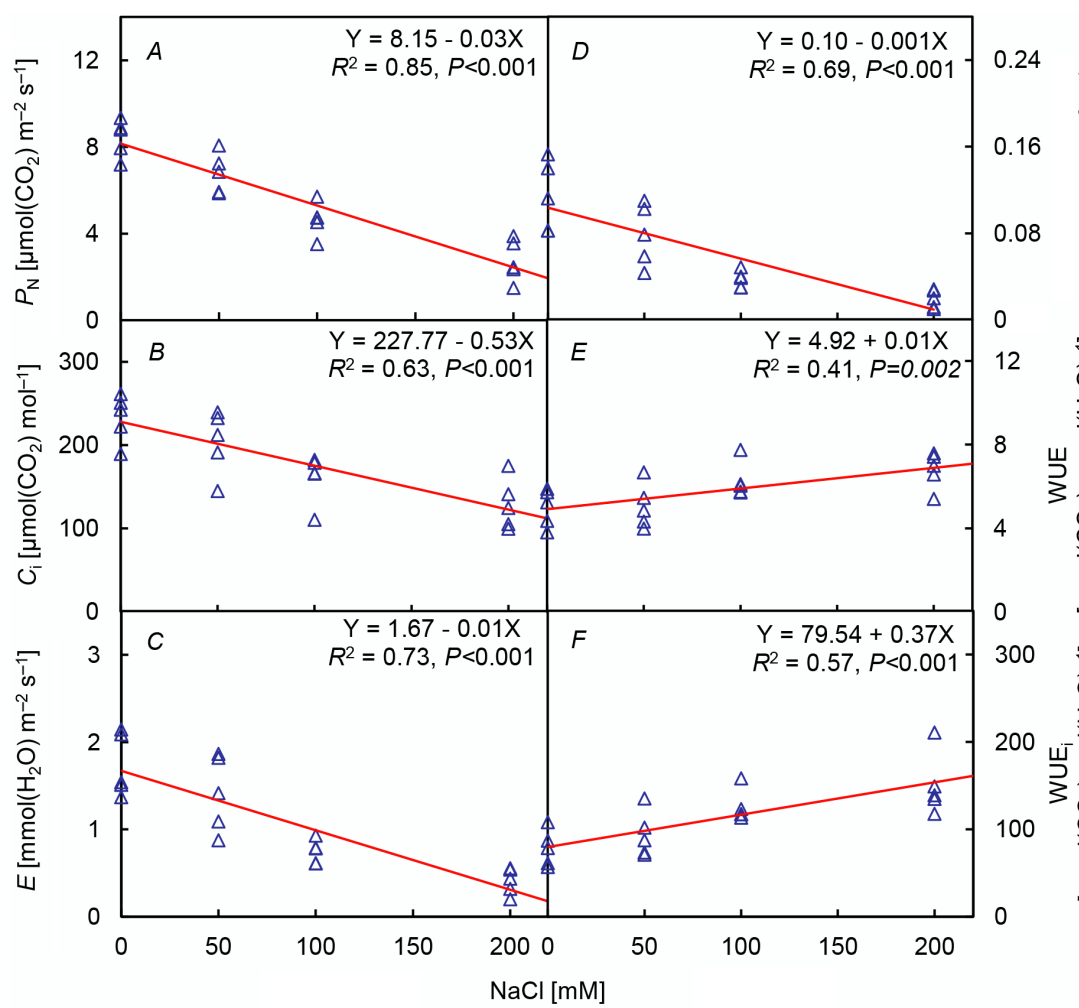

Fig. 4. Changes in net photosynthetic rate $\left(P_{\mathrm{N}}\right)(A)$, internal $\mathrm{CO}_{2}$ concentration $\left(C_{\mathrm{i}}\right)(B)$, transpiration rate $(E)(C)$, stomatal conductance $\left(g_{\mathrm{s}}\right)(D)$, water-use efficiency $(\mathrm{WUE})(E)$, and intrinsic WUE (WUE $)(F)$ of Ziziphus spina-christi seedlings subjected for $21 \mathrm{~d}$ to various $\mathrm{NaCl}$ concentrations $(0,50,100$ or $200 \mathrm{mM}$ ). Lines describing the dependencies were obtained using a linear regression. Values are from four treatments with five replicates $(n=20)$.

Table 1. Correlation coefficients $\left(R^{2}\right)$ between pairs of growth and physiological attributes of Ziziphus spina-christi seedlings subjected for $21 \mathrm{~d}$ to various $\mathrm{NaCl}$ concentrations $(0,50,100$ or $200 \mathrm{mM}){ }^{*},{ }^{* *}-$ significant at $P<0.05$ and $P<0.01$, respectively, ns - not significant; df $(n=20) . C_{\mathrm{i}}$ - intercellular $\mathrm{CO}_{2}$ concentration; DM - dry mass; $E$ - transpiration rate; $g_{s}$ - stomatal conductance; $P_{\mathrm{N}}$ - net photosynthetic rate; RGR - relative growth rate; WUE - water-use efficiency; $\mathrm{WUE}_{\mathrm{i}}$ - intrinsic water-use efficiency; $\psi_{\mathrm{p}}-$ turgor potential; $\psi_{\mathrm{w}}$ - water potential; $\psi_{\pi}-$ osmotic potential.

\begin{tabular}{|c|c|c|c|c|c|c|c|c|c|c|}
\hline Parameters & Shoot DM & Shoot RGR & $C_{\mathrm{i}}$ & $E$ & $g_{\mathrm{s}}$ & $P_{\mathrm{N}}$ & WUE & WUE $_{i}$ & $\psi_{\mathrm{w}}$ & $\psi_{\pi}$ \\
\hline Shoot RGR & $0.99^{* *}$ & & & & & & & & & \\
\hline$C_{\mathrm{i}}$ & $0.59^{* *}$ & $0.60^{* *}$ & & & & & & & & \\
\hline$E$ & $0.70^{* *}$ & $0.72^{* *}$ & $0.91^{* *}$ & & & & & & & \\
\hline$g_{\mathrm{s}}$ & $0.69^{* *}$ & $0.71^{* *}$ & $0.91^{* *}$ & $0.98^{* *}$ & & & & & & \\
\hline$P_{\mathrm{N}}$ & $0.83^{* *}$ & $0.84^{* *}$ & $0.82^{* *}$ & $0.94^{* *}$ & $0.92^{* *}$ & & & & & \\
\hline WUE & $-0.40^{\text {ns }}$ & $-0.42^{\mathrm{ns}}$ & $-0.94^{* *}$ & $-0.85^{* *}$ & $-0.81^{* *}$ & $-0.67^{* *}$ & & & & \\
\hline WUE $_{\mathrm{i}}$ & $-0.52^{*}$ & $-0.53^{*}$ & $-0.95^{* *}$ & $-0.87^{* *}$ & $-0.87^{* *}$ & $-0.78^{* *}$ & $0.92^{* *}$ & & & \\
\hline$\psi_{\mathrm{w}}$ & $0.79^{* *}$ & $0.81^{* *}$ & $0.75^{* *}$ & $0.81^{* *}$ & $0.78^{* *}$ & $0.92^{* *}$ & $-0.58^{* *}$ & $-0.75^{* *}$ & & \\
\hline$\psi_{\pi}$ & $0.82^{* *}$ & $0.84^{* *}$ & $0.82^{* *}$ & $0.85^{* *}$ & $0.83^{* *}$ & $0.90^{* *}$ & $-0.69^{* *}$ & $-0.80^{* *}$ & $0.91^{* *}$ & \\
\hline$\psi_{\mathrm{p}}$ & $-0.67^{* *}$ & $-0.69^{* *}$ & $-0.71^{* *}$ & $-0.72^{* *}$ & $-0.70^{* *}$ & $-0.70^{* *}$ & $0.66^{* *}$ & $0.68^{* *}$ & $-0.61^{* *}$ & $-0.89^{* *}$ \\
\hline
\end{tabular}

and $220 \mathrm{mM}$ (Sohail et al. 2009, Shekafandeh and Takhti 2013, respectively), Z. mauritiana at 131 and $176 \mathrm{mM}$ (Bhatt et al. 2008, Agrawal et al. 2013, respectively), Z. mauritiana grafted on Z. spina-christi at $220 \mathrm{mM}$ (Bhat et al. 2009), and Z. rotundifolia and Z. nummularia at $220 \mathrm{mM}$ (Gupta et al. 2002). Reduction in DM of Ziziphus species might be due to increased osmotic pressure in the root zone after progressive increase of $\mathrm{NaCl}$ salinity in the soil solution, ion accumulation (mainly $\mathrm{Na}^{+}$and $\mathrm{Cl}^{-}$) in plant tissues to toxic concentrations, and excessive concentration of soluble ions that might have resulted in nutrient imbalance in the soil solution and plant tissues (Bhatt et al. 2008, Sohail et al. 2009, Agrawal et al. 2013).
Several research reports also show that plants grown under salt stress manifest acclimation by lowering both leaf $\psi_{\mathrm{w}}$ and $\psi_{\pi}$ (Gorai and Neffati 2011, Gorai et al. 2011). Our data showed that increasing $\mathrm{NaCl}$ salinity was accompanied by a decrease in RWC, $\psi_{\mathrm{w}}$, and $\psi_{\pi}$ of Christ's thorn jujube plants. Maintaining leaf RWC under lowering $\psi_{\mathrm{w}}$ is an important adaptation exhibited by plants to cope with salt stress. Thus, $\psi_{\mathrm{p}}$ could be maintained, and obviously the osmotic adjustment was sufficient to compensate the stem $\psi_{\mathrm{w}}$ decline in these Christ's thorn plants. Numerous studies have reported an increase of the proline content (Gupta et al. 2002, Bhatt et al. 2008, Sankhla et al. 2008, Shekafandeh and Takhti 2013) and activity of antioxidant 


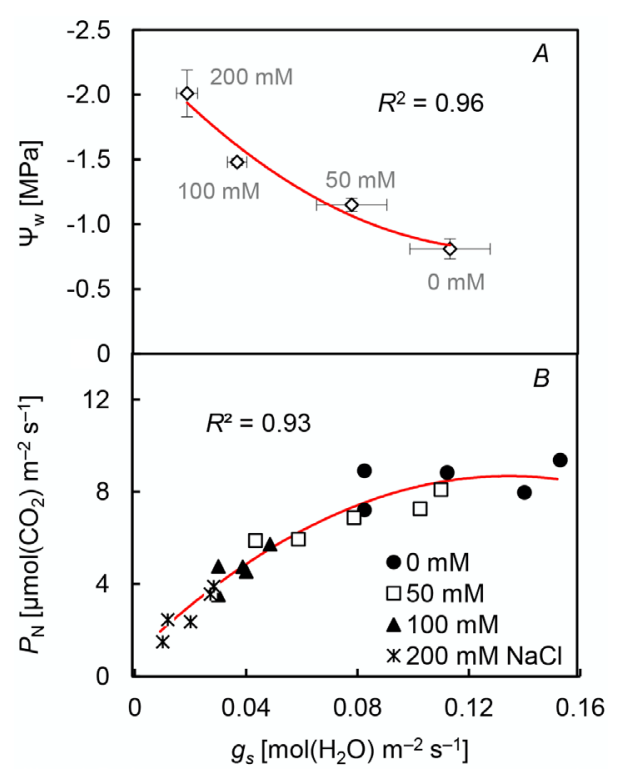

Fig. 5. Relationships between leaf water potential $\left(\psi_{\mathrm{w}}\right)$ and stomatal conductance $\left(g_{\mathrm{s}}\right)(A)$ and net photosynthetic rate $\left(P_{\mathrm{N}}\right)$ and stomatal conductance $\left(g_{\mathrm{s}}\right)(B)$ of Ziziphus spina-christi seedlings subjected for $21 \mathrm{~d}$ to various $\mathrm{NaCl}$ concentrations $(0,50,100$ or $200 \mathrm{mM})$. Lines describing the dependencies were obtained using a polynomial regression. Values are from four treatments with five replicates $(n=20)$.

enzymes (Sankhla et al. 2008, Agrawal et al. 2013) in leaves of Ziziphus species when exposed to $\mathrm{NaCl}$-salinity. $\psi_{\mathrm{w}}$ and $\psi_{\pi}$ were linearly related to RWC, which declined although it still maintained high values. This supports findings on drought-stressed plants of the same genus including Z. mauritiana (Clifford et al. 1998, Kulkarni et al. 2010), $Z$. rotundifolia (Arndt et al. 2001), and Z. lotus (Maraghni et al. 2014, 2019). In the present study, stem $\psi_{\mathrm{w}}$ of NaClstressed seedlings dropped to $-2.0 \mathrm{MPa}$, which is in the range of $\psi_{\mathrm{w}}$ found by Zait and Schwartz (2018) on 12- to 15 -year-old trees of the same species in the field at the end of hot and dry summer $\left(-1.8>\psi_{\mathrm{w}}>-2.2 \mathrm{MPa}\right)$.

Photosynthetic activity is one of the major factors controlling growth (Tezara et al. 2002, Ashraf 2004). The $P_{\mathrm{N}}$ presented here clearly shows a correlation with shoot growth of $Z$. spina-christi treated with increased osmolarity of solutions. The relationship between $P_{\mathrm{N}}$ and $g_{\mathrm{s}}$ reveals a trade-off between water loss and carbon gain experienced by plants in contrasting environments (Gorai et al. 2011, 2015; Maraghni et al. 2019). The present study depicts that $P_{\mathrm{N}}$ and $g_{\mathrm{s}}$ under salt stress were positively associated $(r=$ 0.93, $P<0.01$; Fig. $5 A$ ) and the former variable also had a strong positive relationship with $\psi_{\mathrm{w}}(r=0.93, P<0.01$; Fig. $5 B)$. Thus, $g_{\text {s }}$ plays a strong control over photosynthetic assimilation and the diffusional limitations restricting the supply of $\mathrm{CO}_{2}$ to metabolism of Christ's thorn plants. Our data are in accordance with the findings of Gupta et al. (2002) who showed that $Z$. nummularia and $Z$. rotundifolia are quite tolerant to salinity and the latter species showed a greater photosynthetic performance at high $\mathrm{NaCl}$ salinity. Our results also showed that stressed plants displayed higher WUE and $\mathrm{WUE}_{\mathrm{i}}$ values than that in control plants with increasing $\mathrm{NaCl}$ salinity. This corroborates findings of Zait et al. (2018) on the same species; they showed that improved $\mathrm{WUE}_{\mathrm{i}}$ of one-year-old saplings under intensified drought and salinity stresses was made possible by a greater decline in $g_{s}$.

In conclusion, Christ's thorn jujube grew and survived under severe saline conditions. It was able to overcome salt stress by reducing its photosynthetic performance and plant-water relations. This was achieved by lowering their stem $\psi_{\mathrm{w}}$ and $g_{\mathrm{s}}$ and by maintaining $\psi_{\mathrm{p}}$ as a tolerance mechanism to withstand salt stress.

\section{References}

Agrawal R., Gupta S., Gupta N.K. et al.: Effect of sodium chloride on gas exchange, antioxidative defense mechanism and ion accumulation in different cultivars of Indian jujube (Ziziphus mauritiana L.). - Photosynthetica 51: 95-101, 2013.

Arndt S.K., Clifford S.C., Wanek W. et al.: Physiological and morphologicaladaptations of the fruittreeZiziphusrotundi-folia in response to progressive drought stress. - Tree Physiol. 21: 705-715, 2001.

Ashraf M.: Some important physiological selection criteria for salt tolerance in plants. - Flora 199: 361-376, 2004.

Ashraf M., Foolad M.R.: Roles of glycine betaine and proline in improving plant abiotic stress resistance. - Environ. Exp. Bot. 59: 206-216, 2007.

Bhat N.R., Suleiman M.K., Al-Menaie H. et al:: Response of Zizyphus varieties to irrigation water salinity under arid climatic conditions of Kuwait. - Eur. J. Sci. Res. 29: 543-548, 2009.

Bhatt M.J, Patel A.D, Bhatti P.M., Pandey A.N.: Effect of soil salinity on growth, water status and nutrient accumulation in seedlings of Ziziphus mauritiana (Rhamnaceae). - J. Fruit Ornament. Plant Res. 16: 383-401, 2008.

Blum A., Munns R., Passioura J.B. et al.: Genetically engineered plants resistant to soil drying and salt stress: how to interpret osmotic relations? - Plant Physiol. 110: 1051-1053, 1996.

Cho J.M., Park S.Y., Baek K.: Electrokinetic restoration of saline agricultural lands. - J. Appl. Electrochem. 40: 1085-1093, 2010.

Clifford S.C., Arndt S.K., Corlett J.E. et al.: The role of solute accumulation, osmotic adjustment and changes in cell wall elasticity in drought tolerance in Ziziphus mauritiana (Lamk.).J. Exp. Bot. 49: 967-977, 1998.

Finch-Savage W.E., Leubner-Metzger G.: Seed dormancy and the control of germination. - New Phytol. 171: 501-523, 2006.

Gorai M., Ennajeh M., Khemira H., Neffati M.: Influence of $\mathrm{NaCl}$-salinity on growth, photosynthesis, water relations and solute accumulation in Phragmites australis. - Acta Physiol. Plant. 33: 963-971, 2011.

Gorai M., Laajili W., Santiago L.S., Neffati M.: Rapid recovery of photosynthesis and water relations following soildrying and re-watering is related to the adaptation of desert shrub Ephedra alata subsp. alenda (Ephedraceae) to arid environments. - Environ. Exp. Bot. 109: 113-121, 2015.

Gorai M., Neffati M.: Osmotic adjustment, water relations and growth attributes of the xero-halophyte Reaumuria vermiculata $\mathrm{L}$. (Tamaricaceae) in response to salt stress. Acta Physiol. Plant. 33:1425-1433, 2011.

Gupta N.K., Meena S.K., Gupta S., Khandelwal S.K.: Gas exchange, membrane permeability, and ion uptake in two species of Indian jujube differing in salt tolerance. Photosynthetica 40: 535-539, 2002. 
Hachicha M., Job J.O., Mtimet A.: [Salty soils and salinization in Tunisia.] - Sols de Tunisie, Bulletin de la Direction des Sols 15: 559-564, 1994. [In French]

Hunt R.: Basic Growth Analysis. Plant Growth Analysis for Beginners. Pp. 112. Unwin Hyman, London 1990.

Jaleel C.A., Gopi R., Sankar B. et al.: Alterations in germination, seedling vigour, lipid peroxidation and proline metabolism in Catharanthus roseus seedlings under salt stress. - S. Afr. J. Bot. 73: 190-195, 2007.

Kulkarni M., Schneider B., Raveh E., Tel Zur N.: Leaf anatomical characteristics and physiological responses to short term drought in Ziziphus mauritiana (Lamk.). - Sci. Hortic.Amsterdam 124: 316-322, 2010.

Maraghni M., Gorai M., Neffati M., Van Labeke M.C.: Differential responses to drought stress in leaves and roots of wild jujube, Ziziphus lotus. - Acta Physiol. Plant. 36: 945-953, 2014.

Maraghni M., Gorai M., Neffati M.: Seed germination at different temperatures and water stress levels, and seedling emergence from different depths of Ziziphus lotus. - S. Afr. J. Bot. 76: 453-459, 2010.

Maraghni M., Gorai M., Steppe K. et al.: Coordinated changes in photosynthetic machinery performance and water relations of the xerophytic shrub Ziziphus lotus (L.) Lam. (Rhamnaceae) following soil drying. - Photosynthetica 57: 113-120, 2019.

Morgan J.M.: Osmoregulation and water stress in higher plants. Ann. Rev. Plant Physio. 35: 299-319, 1984.

Munns R.: Comparative physiology of salt and water stress. Plant Cell Environ. 25: 239-250, 2002.

Munns R., Tester M.: Mechanisms of salinity tolerance. - Annu. Rev. Plant Biol. 59: 651-681, 2008.

Nobel P.S.: Physicochemical and Environmental Plant Physiology. Pp. 635. Academic Press, San Diego 1991.

Parida A.K., Das A.B.: Salt tolerance and salinity effects on plants: a review. - Ecotox. Environ. Safe. 60: 324-349, 2005.
Saied A.S., Gebauer J., Hammer K., Buerkert A.: Ziziphus spinachristi (L.) Willd.: A multipurpose fruit tree. - Genet. Resour. Crop Ev. 55: 929-937, 2008.

Sankhla N., Gehlot H.S., Choudhary R. et al.: Eco-physiological studies on Indian desert plants: effect of salt on antioxidant defense systems in Ziziphus spp. - In: Khan M.A., Weber D.J. (ed.): Ecophysiology of High Salinity Tolerant Plants. Pp. 201-213. Springer, Dordrecht 2008.

Scholander P.F., Bradstreet E.D., Hemmingsen E.A., Hammel H.T.: Sap pressure in vascular plants: Negative hydrostatic pressure can be measured in plants. - Science 148: 339-346, 1965.

Shekafandeh A., Takhti S.: Growth and physiological responses of grafted and non-grafted cultivars of Ziziphus spina-christi to salinity. - J. Appl. Bot. Food Qual. 86: 71-78, 2013.

Sohail M., Saied A.S., Gebauer J., Buerkert A.: Effect of $\mathrm{NaCl}$ salinity on growth and mineral composition of Ziziphus spinachristi (L.) Willd. - J. Agr. Rural Dev. Trop. 110: 107-114, 2009.

Sudhersan C., Hussain J.: In vitro clonal propagation of a multipurpose tree, Ziziphus spina-christi (L.) Desf. - Turk. J. Bot. 27: 167-171, 2003.

Tezara W., Mitchell V., Driscoll S.P., Lawlor D.W.: Effects of water deficit and its interaction with $\mathrm{CO}_{2}$ supply on the biochemistry and physiology of photosynthesis in sunflower. J. Exp. Bot. 53: 1781-1791, 2002.

Zait Y., Schwartz A.: Climate-related limitations on photosynthesis and drought-resistance strategies of Ziziphus spinachristi. - Front. For. Glob. Change 1: 3, 2018.

Zait Y., Shtein I., Schwartz A.: Long-term acclimation to drought, salinity and temperature in the thermophilic tree Ziziphus spina-christi: revealing different tradeoffs between mesophyll and stomatal conductance. - Tree Physiol. 00: 1-16, 2018

Zhu J.K.: Plant salt tolerance. - Trends Plant Sci. 6: 66-71, 2001.

(C) The authors. This is an open access article distributed under the terms of the Creative Commons BY-NC-ND Licence. 